\title{
Predictors of Low-Acuity Emergency Department Use by Patients Enrolled in a Family Health Team
}

\author{
Paul Jones, BSc, $\mathrm{MD}^{*}{ }^{\dagger}$; Jennifer Jones, $\mathrm{MD}^{\dagger}$; Kristen O'Brien, BSc, MSc ${ }^{\ddagger}$; \\ Michael Lee-Poy, BSc, MD, MCISc ${ }^{\S}$
}

\section{ABSTRACT}

Background: The primary aim of this study was to determine the characteristics and develop a predictive model describing low acuity users of the emergency department (ED) by patients followed by a family health team (FHT). The secondary aim was to contrast this information with characteristics of high acuity users. We also sought to determine what factors were predictive of leaving without being seen (LWBS).

Methods: This retrospective descriptive correlational study explored characteristics and factors predictive of low acuity ED utilization. The sample included all FHT patients with ED visits in 2011. The last ED record was chosen for review. Sex, age, Canadian Triage and Acuity Scale (CTAS), presenting complaint(s), time of day, day of week, number of visits, and diagnosis were recorded.

Results: Of 1580 patients who visited the ED in 2011, 56\% were CTAS 1-3 visits, 24\% CTAS 4-5 and $20 \%$ had no CTAS recorded. Patients who were older than age 65 were approximately half as likely to have a CTAS level of 4-5 compared to younger patients $(\mathrm{OR}=0.605, \mathrm{Cl}=$ $0.441,0.829)$. Patients older than age 65 were 1.75 times more likely to be CTAS level $1-2(\mathrm{OR}=1.745, \mathrm{Cl}=1.277,2.383)$. Patients who went to the ED during the day were less likely to LWBS compared to night visits $(O R=0.697$, $\mathrm{Cl}=0.532,0.912$ ).

Interpretation: Most low acuity ED utilization is by patients under the age of 65, while high acuity ED utilization is more common among patients older than age 65. Patients are more likely to LWBS during late evening and overnight periods (9 pm-7 am).

\section{RÉSUMÉ}

Contexte: L'étude avait pour objectifs principaux de déterminer les caractéristiques d'utilisation des services d'urgence (SU) pour des troubles peu graves par des patients suivis par une équipe de la santé de la famille (ESF), et d'élaborer un modèle prévisionnel d'utilisation de ce genre. L'objectif secondaire consistait en la comparaison des caractéristiques des utilisateurs pour des troubles peu graves avec celles des utilisateurs pour des troubles graves. Les auteurs cherchaient également à déterminer des facteurs prévisionnels de départ des patients sans avoir été examinés.

Méthode: II s'agit d'une étude rétrospective, descriptive et corrélationnelle, portant sur les caractéristiques et les facteurs prévisionnels d'utilisation des SU pour des troubles peu graves. L'échantillon comprenait tous les patients appartenant à une ESF, qui étaient allés consulter au SU en 2011; le dossier retenu pour l'examen était celui de la dernière consultation au SU. Ont été consignés le sexe, I'âge, le degré de gravité selon l'Échelle canadienne de triage et de gravité (ECTG), les motifs de consultation, I'heure du jour, le jour de la semaine, le nombre de consultations ainsi que le diagnostic.

Résultats: Sur 1580 patients qui sont allés au SU en 2011, $56 \%$ présentaient des troubles d'une gravité de 1 à 3 selon I'ECTG; $24 \%$, des troubles d'une gravité de 4 ou 5 selon I'ECTG et $20 \%$, des troubles d'une gravité non consignée au dossier. Les patients de plus de 65 ans avaient environ la moitié des risques de présenter des troubles d'une gravité 4 ou 5 selon I'ECTG comparativement aux jeunes patients (risque relatif approché [RRA]: 0,605; IC: 0,441-0,829). Par contre, les patients de plus de 65 ans avaient 1,75 fois plus de risques de présenter des troubles d'une gravité 1 ou 2 selon I'ECTG (RRA: 1,745; IC: 1,277-2,383) que ceux de moins de 65 ans. Enfin, les patients qui étaient allés au SU le jour étaient moins susceptibles de partir sans avoir été examinés que ceux qui y étaient allés la nuit (RRA: 0,697: IC: 0,532-0,912).

Interprétation: La plupart des consultations données au SU pour des troubles peu graves le sont pour des patients de moins de 65 ans, tandis que les consultations données au SU pour des troubles graves le sont plus souvent pour des patients de plus de 65 ans. Par ailleurs, les patients qui vont au

From the *Department of Family Medicine, McMaster University, Hamilton, Ontario, Canada; †The Centre for Family Medicine FHT, Kitchener, Ontario, Canada; ¥Population Cancer Research Program, Department of Pediatrics, Dalhousie University, Halifax, Nova Scotia, Canada; and §Department of Family Medicine, Western University, London, Ontario, Canada

Correspondence to: Dr. Paul Jones, BSc, MD, McMaster University, Family Medicine, The Centre for Family Medicine Integrated Health Building, 10 B Victoria St., S Kitchener, Ontario, N2G 1C5. Email: paul.jones@medportal.ca 
SU en fin de soirée ou la nuit ( $21 \mathrm{~h}-7 \mathrm{~h}$ ) sont plus susceptibles de partir sans avoir été examinés que ceux qui y vont le jour.
Keywords: Emergency Department, Low Acuity, Triage, CTAS 4, CTAS 5, Family Health Team, ED Utilization

\section{INTRODUCTION}

There has been increasing interest in determining why patients use the emergency department (ED) for non-urgent or low-acuity Canadian Triage and Acuity Scale (CTAS) level 4-5 visits. In Ontario, reducing ED wait times is a key component of the provincial ED and Alternate Level of Care strategies. In the Waterloo Wellington Local Health Integration Network (WWLHIN), low-acuity CTAS 4-5 ED visits are considered to significantly contribute to increased ED wait times. The WWLHIN identified the need to better understand the reasons for CTAS 4-5 patient visits as a key area for future research. A WWLHIN report indicated that "[45\%] of total ED visits were non-urgent (CTAS 4-5), [and] these people could have been managed in another setting". ${ }^{1}$ The stated goal of the WWLHIN is to decrease CTAS 4-5 ED utilization by $10 \%$ and ensure appropriate use of ED resources. ${ }^{1} \mathrm{~A}$ 2005 Canadian Institute for Health Information (CIHI) study investigating ED wait times found that $57 \%$ of ED visits were for less urgent (CTAS 4) or non-urgent (CTAS 5) reasons. ${ }^{2}$

The Centre for Family Medicine is a family health team (FHT) in the region of Waterloo comprised of family physicians, interdisciplinary health care providers, support staff, and medical learners (residents and medical students). At the time of the study, the team consisted of 16 family physicians who had a total patient roster of about 20,000 patients. During 2011, exact clinic hours of operation varied by physician. Most physicians worked Monday to Friday, and clinics ran between 8 am and $5 \mathrm{pm}$. After-hours clinics were available Monday to Thursday, 5 pm to 7 pm; Friday, 3 pm to $5 \mathrm{pm}$; and Saturday, 10 am to $1 \mathrm{pm}$. During 2011, there was no after-hours clinic available on Sunday. Outside of clinic hours, patients had access to a telephone health advisory service (THAS); and a resident and staff physician were on call if THAS nurses had questions that required a physician. There was variability among the 16 physicians in the FHT in terms of same day and next day bookings. In 2012-2013, the FHT took steps toward advanced access by reducing the time to next available appointment and ensuring that physicians kept more appointment slots available for same day bookings.

In 2011, the WWLHIN had a patient population of 775,000 , with $277,880 \mathrm{ED}$ visits or $366.6 \mathrm{ED}$ visits per 1,000 patients. $^{3}$

Currently, very little is known about ED use by patients rostered to FHT in Ontario. A recent report comparing primary care models in Ontario showed that there was typically one visit per FHT patient per year in 2008/09 and 0.9 visits per FHT patient per year in 2009/10. ${ }^{4}$ By better understanding why FHT patients present to the ED, opportunities can be identified for primary care quality improvement that mayhelp reduce low-acuity visits to EDs in Ontario.

The primary aim of this study was to determine the characteristics of CTAS 4-5 patients and develop a predictive model of low-acuity ED utilization. The secondary aim was to compare this information with characteristics of CTAS 1-2 patients and develop a predictive model of high-acuity ED utilization. The study also sought to determine what factors were predictive of leaving without being seen (LWBS).

\section{METHODS}

This retrospective correlational study explored characteristics of low-acuity ED utilization by patients enrolled in an FHT and factors predictive of low-acuity ED utilization. Research Ethics Board approval was obtained through Hamilton Health Sciences and McMaster University, Faculty of Health Sciences.

At the Centre for Family Medicine, ED face sheets are scanned into the electronic medical record (EMR) and labeled as "emergency physician/emergency medicine." The term "emergency physician/emergency medicine" was searched in which the occurrence date was later than January 1, 2011 and earlier than December 31, 2011 (using the search feature in Practice Solutions Software Inc., 2002-2012 - PS Suite 5.1; 243-A, Jul 20, 2012). The last recorded ED visit in 2011 was used to extract data. The total number of ED visits during 2011 per patient was recorded. The sample included all Centre for Family Medicine FHT patients 
with ED visits in $2011(n=1580)$; there were a total of 2230 visits.

The dependent variable was low-acuity (CTAS 4-5) ED visits. ${ }^{6-8}$ Independent variables included: age, sex, time of day, day of the week, presenting complaint, number of ED visits, diagnosis, and result of visit.

The presenting complaint was recorded as it was written on the ED record. The data were coded using the Canadian Emergency Department Information System (CEDIS) Presenting Complaint List (V2.0 - April 2012) ${ }^{9}$, and the presenting complaints were used for analysis. The final diagnosis was recorded in a similar manner, and the data were coded using the Canadian Emergency Department Diagnosis Shortlist (CED-DxS) (V.2.0 - April 2012) ${ }^{10}$, and the diagnoses were used for analysis.

After evaluating for normality, basic descriptive statistics were used to describe demographics, time of day, result of visit, and presenting complaints of the targeted population of low-acuity (CTAS 4-5) ED use compared to high-acuity (CTAS 1-2) ED use.

Variables that were commonly typed rather than handwritten were preferentially selected in the scanned copies of the ED record, since extracting variables from the handwritten ED record was difficult. As a result, some variables were missing (i.e., diagnosis and result of visit [disposition]). Variables typically typed (i.e., computerentered rather than handwritten) include sex, age, day of the week, time of day, and CTAS level. ${ }^{5}$ After initial descriptive statistics were completed, selected variables were tested for predictive value with univariate and multivariate logistic regression models. Variables were selected based on clinical relevance: age ( $\geq 65$ versus $<65$ years of age), sex (male versus female), time of visit (between 7 am and $9 \mathrm{pm}$ versus between $9 \mathrm{pm}$ and $7 \mathrm{am}$ ), and the number of visits ( $\geq 3$ versus $<3$ visits). Adjusted odds ratios were calculated for CTAS levels 4-5 based on age cutoffs, while controlling for sex, day of the week of the visit, and whether the patient was a frequent ED user with $\geq 3 \mathrm{ED}$ visits in one year. Adjusted odds ratios were calculated for CTAS 1-2 patients based on age cutoffs, while controlling for sex and whether the patient was a frequent ED user.

Predictors of theoretical relevance were tested by univariate logistic regression models and incorporated into the final multivariate logistic regression model to generate odds ratios predicting low acuity and high acuity ED utilization and LWBS. All analyses were performed using SAS statistical software version 9.3 (SAS Institute, Cary, NC).

\section{RESULTS}

In 2011, there were 1580 patients who visited the ED. Females accounted for $49.9 \%$ of the study population; males accounted for $49.8 \%$. The patient ages ranged from 1 month to 99 years of age, with a mean age of 43 (Figure 1). CTAS $1-3$ accounted for $56 \%(n=884)$ of visits, CTAS $4-5$ accounted for $24 \%(n=387)$ of visits, and $20 \%(n=309)$ of visits had no CTAS level recorded (Table 1).

Analysis of time of day of ED use showed a first peak at $11 \mathrm{am}$ and second peak at $7 \mathrm{pm}$ for CTAS 4-5 level patients (Figure 2). There was no significant difference in ED use by day of the week, however, there was a slight increase in ED use on Sundays and Mondays (Figure 3).

The primary reason for patient presentation to the ED was cardiovascular complaint, followed by orthopedic and gastrointestinal complaints (Figure 4). The majority of patients $(n=1,200)$ had one visit to the ED during the study period, 221 patients had two visits, and 74 patients had three visits. The highest ED use by a single patient during the study period was 25 visits.

The leading diagnostic categories for CTAS 4-5 patients were injury, poisoning, and other $(n=121)$. The next most common diagnostic category was diseases of the musculoskeletal system and connective tissue $(n=56)$ (Figure 5).

The result of each ED visit and final disposition was determined (Figure 6). The majority (71.8\%) of patients were discharged home from the ED $(n=1135)$. Admissions accounted for $4.4 \%(n=69)$ of ED visits, $4.6 \%(n=72)$ of patients LWBS, and $1.1 \%(n=17)$ of patients were placed in a clinical decision unit (CDU) with the expected disposition of "discharge", after obtaining diagnostic test results during a period of observation. A small number of patients were transferred to another institution, $0.6 \%(n=9)$. Patients leaving against medical advice accounted for $0.3 \%(n=4)$ visits. During the study period, one ED patient death was recorded $(0.1 \%)$. No disposition was recorded for $17.3 \%(n=273)$ visits.

Age greater than 65 years was associated with lower ED use by patients triaged to CTAS 4-5 (OR 0.61 [0.44-0.83], $p=0.0017$ ) (Table 2). Differences between sexes, day of the week, and total number of visits by a patient were not found to be statistically significant predictors in the CTAS 4-5 patient group. 


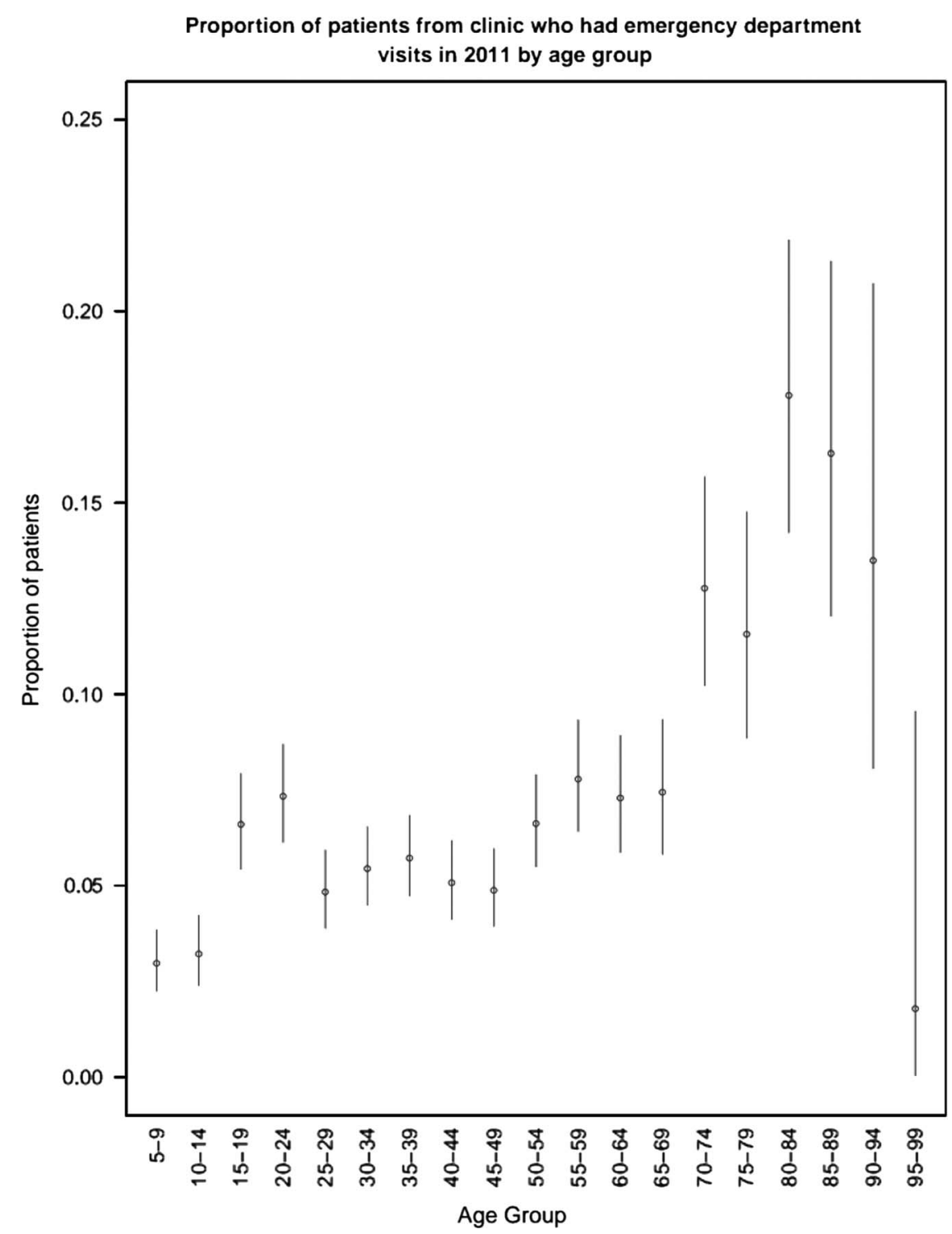

Figure 1. Number of ED Visits by Age Group

*Patients aged 0-4 were excluded because of confounding demographic data due to non-rostered new born care patients.

Table 1. Demographic comparison between high (1-3) and low acuity (4-5) CTAS levels and no CTAS

\begin{tabular}{lcccc} 
& CTAS 1-3 & CTAS 4-5 & No CTAS \\
\hline Number of Patient Encounters & 884 & 387 & 309 \\
Average Age & 45.9 & 38.9 & 43.2 \\
Female \% & 51 & 50 & 47 \\
Average Number of Visits & 1.41 & 1.52 & 1.43 \\
\hline
\end{tabular}

Multivariate logistic regression analysis showed that age $>65$ also predicted ED use in CTAS 1-2 patients (OR 1.75 [1.28-2.38], $p=0.0005$ ). Differences between sexes, day of the week, and total number of visits by a patient were not found to be statistically significant in the CTAS 1-2 patient group (Table 3).

Patients who went to the ED during the day were less likely to LWBS compared to patients who went at night (OR 0.70 [0.53-0.91], $p=0.0173$ ). Patients who went to the ED at night were 1.4 times more likely to LWBS compared to patients who went to the ED during the day (Table 4).

\section{DISCUSSION}

In 2011, there were 2230 ED visits by 1580 patients, representing approximately $7.9 \%$ of the FHT practice 


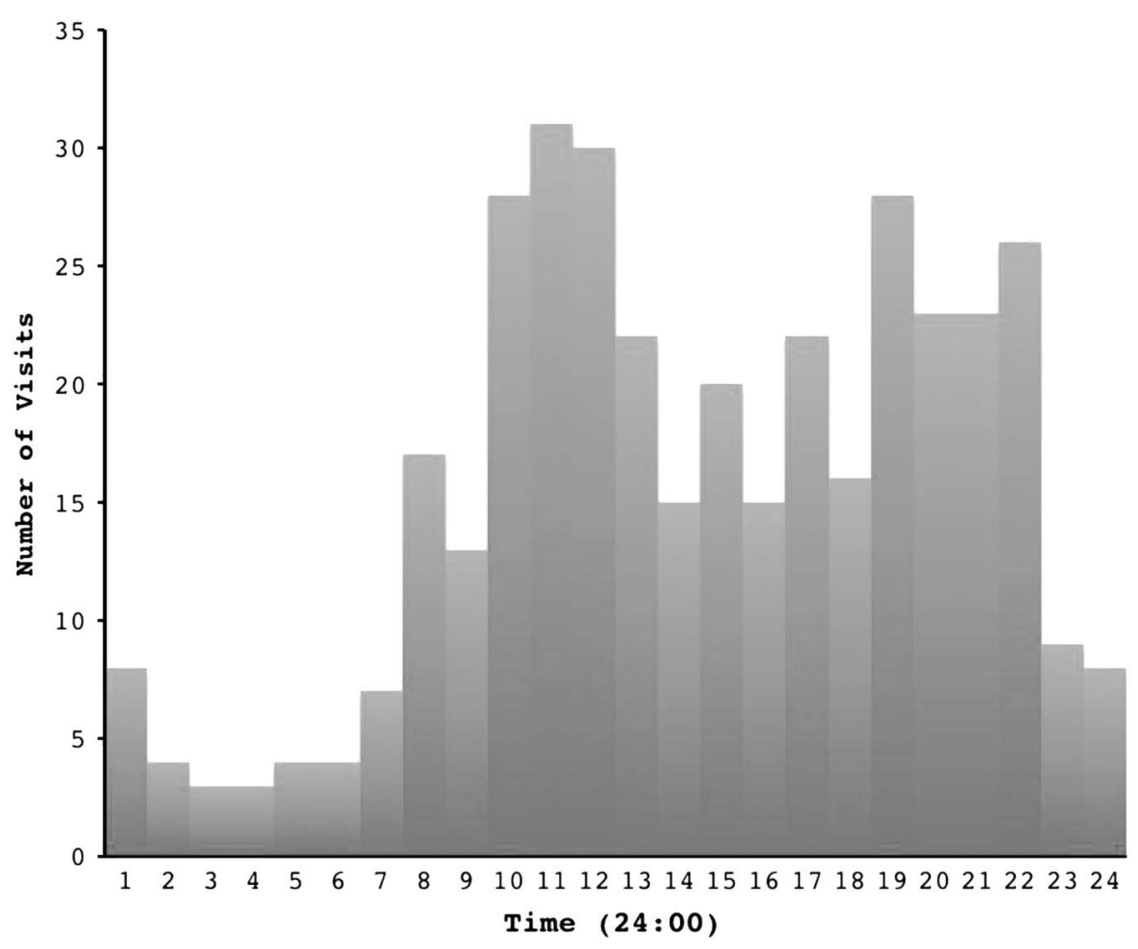

Figure 2. Frequency of CTAS 4 and 5 visits by time $(24: 00 \mathrm{~h})$

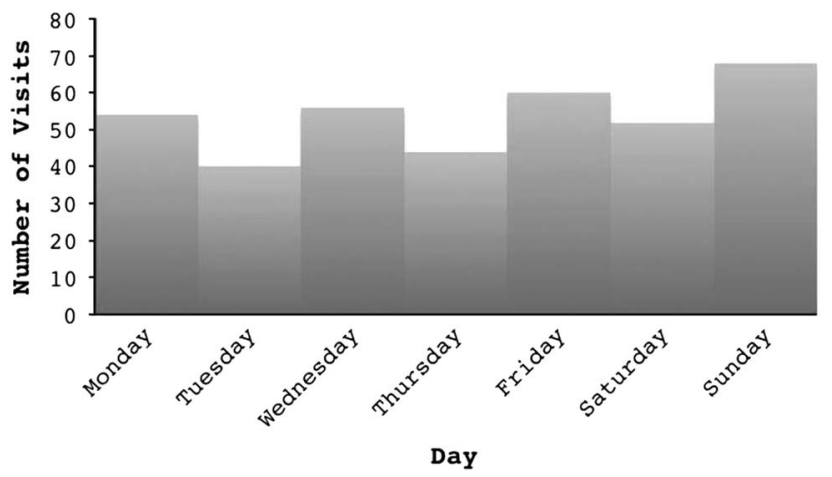

Figure 3. CTAS 4 and 5 ED visits by day of the week

roster. Most patients had one visit and were discharged home from the ED. A small percentage of patients had multiple ED visits, which tended to be for high and moderate acuity presenting complaints such as chest pain, shortness of breath, and abdominal pain.

Much discussion in the literature has focused on trying to identify patients with low-acuity presenting complaints to see if they might be safely diverted away from the ED. ${ }^{11-14}$ A recent study demonstrated limited concordance between presenting complaints and ED discharge diagnoses, suggesting that presenting complaints are unable to accurately identify non-emergent ED use. ${ }^{11}$ The study found that only $6.3 \%$ of patients

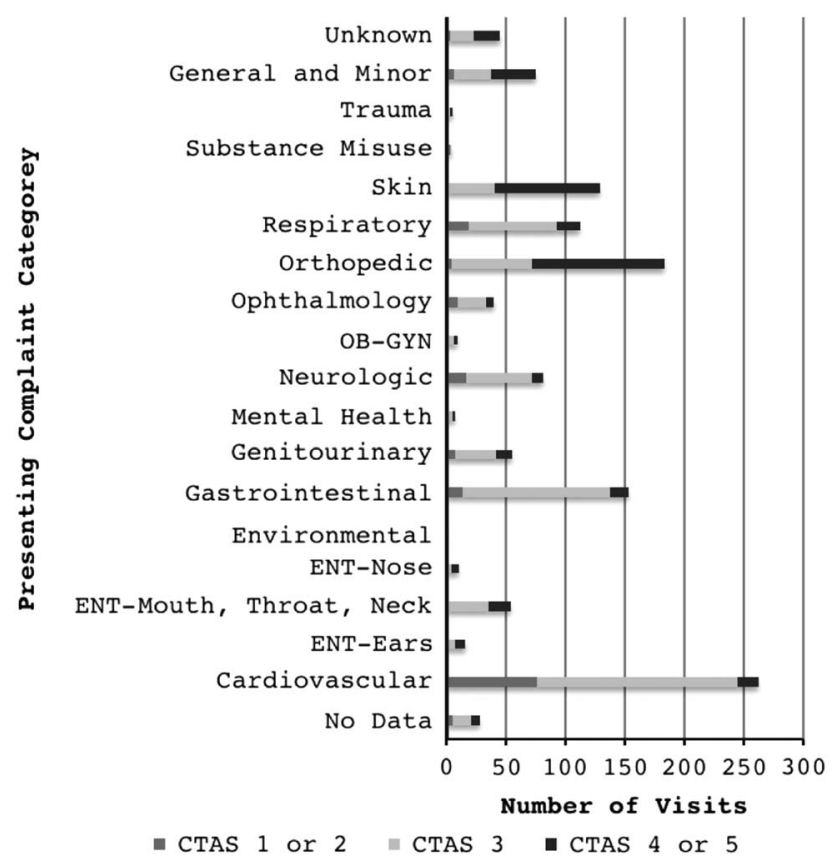

Figure 4. Frequency of presenting complaints by CTAS grouping.

presenting to the ED had primary care-treatable diagnoses based on discharge diagnosis and an algorithm. ${ }^{11}$

Another study examined reasons for patient presentation to the ED in Edmonton, Alberta. ${ }^{12}$ The study 


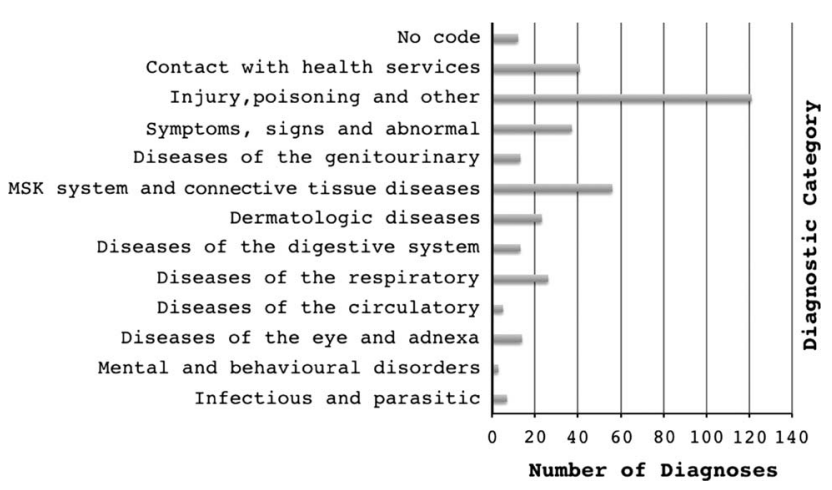

Figure 5. CTAS 4 and 5 diagnoses by diagnostic category

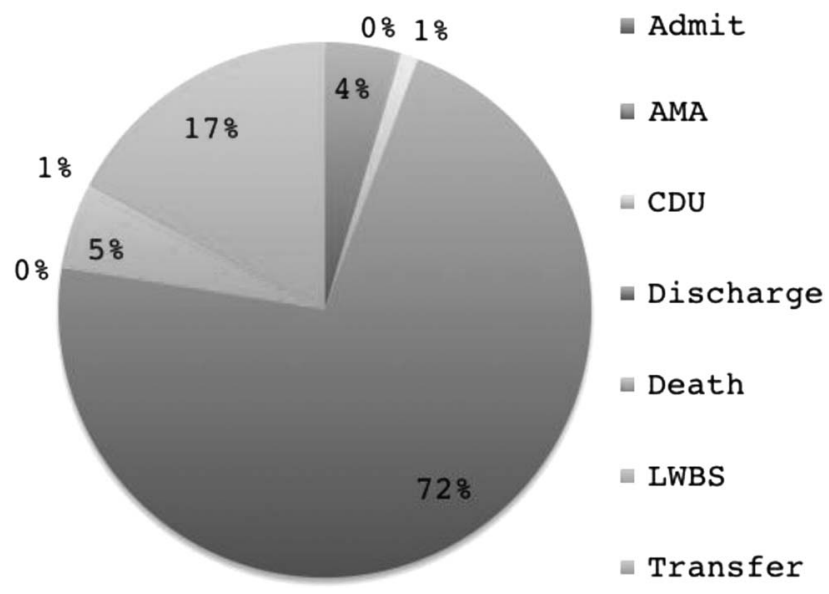

Figure 6. Outcome of ER visit (disposition)

found that many patients made concerted efforts to avoid ED visits; $61 \%$ of patients sought alternative care before visiting the ED. ${ }^{12}$ The role of health professionals and systems in driving ED overuse must be considered. Strikingly, $47 \%$ of patients who sought alternatives to the ED made contact with a physician's office. $^{12}$ Patients who called a physician's office were directed to visit a family physician (3\%), a health care professional (9\%), or the ED (63\%). The study also found that $14 \%$ of patients contacted a regional health line. ${ }^{12}$ One study found regional health lines recommended going to the $\mathrm{ED}(58 \%)$, seeing a primary care physician $(6 \%)$, or seeing another health care professional $(3 \%){ }^{3}$ Patients who called a physician's office or regional health line were almost ten times more likely to be directed to visit the ED than a family physician. $^{3}$

Limitations of the study include the relatively small sample size and retrospective chart review design.
Because the study relied on searching the FHT EMR for scanned ED face sheets, all ED encounters may not have been captured. Another limitation, which may affect generalizability, is that all patients were from a single FHT located in Kitchener, Ontario, Canada. All visits were during 2011, so there might be variation year to year in terms of patterns of ED use. The study did not account for prior health status of patients, which could be a confounding factor. Because not all ED visits were subject to data extraction due to time and resource limitations, it was decided to gather more variables as potential predictors from fewer patients, rather than fewer variables for more patients. This method did not consider that a lack of relationship between reasons for a patient's ED visits. Finally, the study excluded patients aged 0-4 years of age (Figure 1), because the graph displays the ratio of ED visits compared to numbers of patients of that particular age group in the FHT. The confounding issue in the 0-4 age group is that a number of the physicians provided newborn care to children who were not rostered as part of the FHT. These patients were captured in the EMR census data, which artificially inflated the number of young patients. Data from children aged 0-4 years were included in the predictive models and included when determining the descriptive statistics of the study population.

Further research could make use of a prospective methodology to see if similar patterns of ED utilization are seen across multiple years or at other FHTs throughout Ontario. This methodology could also be used to compare ED utilization by patients in other models of primary care. For patients with multiple visits, a method to randomly sample an ED encounter for analysis might minimize any risk of bias. Future research could also look at the use of the FHT before and after the ED encounter. Additional research could determine if there was a relationship between high and low use of FHT resources and visits to the ED. Another avenue for future research is to compare FHT patients who had ED visits to FHT patients who did not have ED visits. For patients with multiple visits, future work could determine whether there is a correlation within each patient for the urgency of his or her visits.

The study findings should help inform decisionmaking regarding the provision of care for FHT patients. The findings of this study suggest a number of improvements, such as providing simple laceration repair during clinic and after-hours clinics. The FHT 
Table 2. The association between patient characteristics and having a CTAS Level of 4 or 5

\begin{tabular}{|c|c|c|c|c|}
\hline Characteristic & & Unadjusted OR & Adjusted OR* & $p$ value for $A O R$ \\
\hline \multirow[t]{2}{*}{ Age } & $\geq 65$ years of age & $0.567(0.416,0.773)$ & $0.605(0.441,0.829)$ & 0.0017 \\
\hline & $<65$ years of age & 1 & 1 & \\
\hline \multirow[t]{2}{*}{ Sex } & Male & $1.030(0.816,1.299)$ & $0.983(0.776,1.247)$ & 0.8902 \\
\hline & Female & 1 & 1 & \\
\hline \multirow[t]{7}{*}{ Day of Week } & Monday & $0.781(0.515,1.184)$ & $0.785(0.517,1.194)$ & 0.4210 \\
\hline & Tuesday & $0.686(0.436,1.077)$ & $0.700(0.444,1.102)$ & 0.1561 \\
\hline & Wednesday & $1.038(0.680,1.585)$ & $1.026(0.670,1.571)$ & 0.3118 \\
\hline & Thursday & $0.710(0.457,1.103)$ & $0.727(0.466,1.137)$ & 0.2247 \\
\hline & Friday & $1.060(0.701,1.604)$ & $1.058(0.697,1.607)$ & 0.2078 \\
\hline & Saturday & $0.943(0.618,1.437)$ & $0.960(0.628,1.468)$ & 0.5680 \\
\hline & Sunday & 1 & 1 & \\
\hline \multirow{2}{*}{ Number of Visits } & $\geq 3$ visits & $1.082(0.723,1.619)$ & $1.163(0.767,1.763)$ & 0.4764 \\
\hline & $<3$ visits & 1 & 1 & \\
\hline
\end{tabular}

\begin{tabular}{|c|c|c|c|c|}
\hline Characteristic & & Unadjusted OR & Adjusted OR & $p$ value for $A O R$ \\
\hline \multirow[t]{2}{*}{ Age } & $\geq 65$ years of age & $1.764(1.294,2.405)$ & $1.745(1.277,2.383)$ & 0.0005 \\
\hline & $<65$ years of age & 1 & 1 & \\
\hline \multirow[t]{2}{*}{ Sex } & Male & $0.971(0.770,1.225)$ & $0.975(0.772,1.232)$ & 0.8341 \\
\hline & Female & 1 & 1 & \\
\hline \multirow[t]{2}{*}{ Number of Visits } & $\geq 3$ visits & $0.924(0.618,1.383)$ & $0.866(0.576,1.301)$ & 0.4876 \\
\hline & $<3$ visits & 1 & 1 & \\
\hline
\end{tabular}

Table 4. The association between patient characteristics and LWBS (leaving without being seen)

\begin{tabular}{|c|c|c|c|c|}
\hline Characteristic & & Unadjusted OR & Adjusted OR & $p$ value for $A O R$ \\
\hline \multirow[t]{2}{*}{ Age } & $\geq 65$ years of age & $1.626(1.247,2.122)$ & $1.654(1.262,2.168)$ & 0.0003 \\
\hline & $<65$ years of age & 1 & 1 & \\
\hline \multirow[t]{2}{*}{ Sex } & Male & $1.249(0.996,1.567)$ & $1.231(0.978,1.549)$ & 0.0761 \\
\hline & Female & 1 & 1 & \\
\hline \multirow[t]{2}{*}{ Time of Day } & Between 7:00 h-21:00 h & $0.697(0.532,0.912)$ & $0.720(0.549,0.944)$ & 0.0173 \\
\hline & Between 21:00 h-7:00 h & 1 & 1 & \\
\hline \multirow[t]{2}{*}{ Number of Visits } & $\geq 3$ visits & $1.274(0.863,1.879)$ & $1.183(0.796,1.757)$ & 0.4051 \\
\hline & $<3$ visits & 1 & 1 & \\
\hline
\end{tabular}

should consider repatriating patients on anticoagulation therapy for venous thromboembolism for point-of-care INR testing, rather than requiring return visits to the ED. Other changes to consider include shifting on call clinics to start at $7 \mathrm{pm}$ to meet peak demand and educating patients about expected wait times in ED for low-acuity complaints. Implementing these suggested changes could provide patients with better alternatives to the ED; these targeted interventions could better serve FHT patients and help reduce low-acuity ED use.

\section{CONCLUSIONS}

Most low-acuity ED use was by patients under the age of 65 , whereas high-acuity ED use was more common among patients with an age greater than 65 . Patients are 
more likely to LWBS during the night (9 pm to $7 \mathrm{am}$ ). These findings suggest that patients younger than age 65 are most likely to go to the ED with low-acuity or non-urgent complaints.

Competing Interests: None declared.

\section{REFERENCES}

1. Waterloo Wellington Local Health Integration Network. Annual Business Plan 2010-2011 to 2012-2013. July 52010.

2. Canadian Institute for Health Information. Understanding Emergency Department Wait Times. Ottawa, Ontario: Canadian Institute for Health Information, 2005.

3. Glazier RH, Zagorski BM, Rayner J. Comparison of Primary Care Models in Ontario by Demographics, Case Mix and Emergency Department Use 2008/09 to 2009/10. ICES Investigative Report. March 6, 2012.

4. Population Health Profile: Waterloo Wellington LHIN. December 2013:1-4.

5. Lin D, Worster A. Predictors of admission to hospital of patients triaged as nonurgent using the Canadian Triage and Acuity Scale. C7EM 2013;15(6):353-8.

6. Beveridge R, Clarke B, Janes L, et al. Canadian emergency department triage and acuity scale: implementation guidelines. CFEM 1999;1(3 Suppl):S2-32.
7. Manos D, Petrie DA, Beveridge RC, et al. Inter-observer agreement using the Canadian Emergency Department Triage and Acuity Scale. CFEM 2002;4:16-22.

8. Bullard MJ, Unger B, Spence J, et al. Revisions to the Canadian Emergency Department Triage and Acuity Scale (CTAS) adult guidelines. CFEM 2008;10: 136-142.

9. Moe J, Bailey AL, Oland R, et al. Defining, quantifying, and characterizing adult frequent users of a suburban Canadian emergency department. CFEM 2013;15(4): 214-226.

10. Canadian Emergency Department Information System (CEDIS) Presenting Complaint List (V2.0 - April 2012).

11. Canadian Emergency Department Diagnosis Shortlist (CED-DxS) (V2.0 - April 2012).

12. Raven M, Lowe RA, Maselli J, et al. Comparison of presenting complaint vs discharge diagnosis for identifying "nonemergency" emergency department visits. $7 A M A$ 2013;309(11):1145-53.

13. Han A, Ospina MB, Blitz S, et al. Patients presenting to the emergency department: the use of other health care services and reasons for presentation. CFEM 2007; $9(6): 428-34$.

14. Adams J.G. Emergency department overuse - preceptions and solutions. 7AMA 2013;309(11):1173-4.

15. Schull MJ, Kiss A, Szalai JP. The effect of low-complexity patients on emergency department waiting times. Ann Emerg Med 2007;49(3):257-64, 264.e1. 